\begin{abstract}
Iranica
Abstracta Iranica Revue bibliographique pour le domaine irano-aryen

Volume 32-33 | 2013

Comptes rendus des publications de 2009-2010
\end{abstract}

\title{
Antonio Sagona, Paul Zimansky. Ancient Turkey
}

\section{Astrid Nunn}

\section{OpenEdition}

\section{Journals}

\section{Édition électronique}

URL : http://journals.openedition.org/abstractairanica/40411

DOI : 10.4000/abstractairanica.40411

ISSN : 1961-960X

Éditeur :

CNRS (UMR 7528 Mondes iraniens et indiens), Éditions de l'IFRI

\section{Édition imprimée}

Date de publication : 1 décembre 2013

ISSN : 0240-8910

\section{Référence électronique}

Astrid Nunn, «Antonio Sagona, Paul Zimansky. Ancient Turkey», Abstracta Iranica [En ligne], Volume 32-33 | 2013, document 115, mis en ligne le 01 juillet 2016, consulté le 27 septembre 2020. URL : http://journals.openedition.org/abstractairanica/40411; DOI : https://doi.org/10.4000/ abstractairanica.40411

Ce document a été généré automatiquement le 27 septembre 2020.

Tous droits réservés 


\title{
Antonio Sagona, Paul Zimansky. Ancient Turkey
}

\author{
Astrid Nunn
}

\section{RÉFÉRENCE}

Antonio Sagona, Paul Zimansky. Ancient Turkey. Routledge, 2009, 420 p.

1 Cette nouvelle introduction ne consacre que peu de place à l'époque achéménide. Le chapitre 10 "New cultures in the West: The Aegean coast, Phrygia, and Lydia (1200-550 BC)" se termine par "The Achaemenid conquest and its antecedent" (p. 367-370). Ce chapitre se concentre sur le Kerkenes Dağ, un site certes très intéressant, mais qui, redaté, n'est plus un témoin de cette époque en Anatolie (voir Abs. Ir. 29, 2006, c.r. n 81 et aussi Abs. Ir. 31, 2008, c.r. n $^{\circ} 71$ ).

\section{AUTEURS}

ASTRID NUNN

Université de Munich 